\title{
Pemanfaatan dan Strategi Pemasaran Olahan Bambu
}

\author{
Agam Nicholas ${ }^{1}$, Dimas Elang Wicaksono ${ }^{2}$, Febryanto Pratama ${ }^{3}$, Hans Audianto Kurniawan ${ }^{4}$, Hendrianto $^{5}$, Hernandi Aditya \\ Prong $^{6}$, Hizkia Pilar Tiarso ${ }^{7}$, Laksmay Alshika Purmitasari ${ }^{8}$, Satrio Adi Pamungkas ${ }^{9}$, Wemar Adhie Lovely ${ }^{10}$, Meganusa \\ Ludvianto ${ }^{11}$ \\ Universitas Atma Jaya Yogyakarta’Jl. Babarsari No.44, Janti, Caturtunggal, Kec. Depok, Kabupaten Sleman, Daerah \\ Istimewa Yogyakarta 55281 \\ Email : meganusa.ludvianto@uajy.ac.id
}

\begin{abstract}
This journal was created to fulfill the requirements for completing Kuliah Kerja Nyata ke 79 (KKN) activity that was carried out by Atma Jaya Yogyakarta University in 2021. The location that was used as the object of KKN for the writing team was Serut village which is in Gedangsari sub-district, Gunungkidul district. , the province of the Special Region of Yogyakarta. The theme raised by the writing team was the potential of Serut village. The writing team searched for data and information about Serut village via the internet by analyzing it through the official Serut village website and other related websites, and several related journals. The writing team found that Serut village's potential is the potential for a tourism village and the potential for natural resources, specifically the producer of Jati wood and bamboo wood. This program is expected to be able to help Serut villagers to be able to further develop the potential of their village.
\end{abstract}

Keywords - Village Potentials, Tourism Village, Village Natural Resource Potentials.

\section{PENDAHULUAN}

Desa Serut merupakan desa yang terletak di kecamatan Gedangsari kabupaten Gunung Kidul. Desa Serut berada di sebelah Utara Gunung Kidul dengan ketinggian $200 \mathrm{mdpl}$. Utara desa Serut merupakan desa Ngandong dan desa Kragilan kecamatan Gantiwarno. Selatan desa Serut merupakan desa Terbah kecamatan Patuk. Barat desa Serut merupakan desa Gayamharjo dan timur desa Serut merupakan desa Sampang yang dimana

masih satu kecamatan dengan desa Serut. Desa Serut dengan luas tanah sebesar 858,8 Ha memiliki kondisi alam berupa dataran tinggi. Akses untuk masuk ke desa Serut sudah dapat dilalui oleh transportasi berupa motor dan mobil dikarenakan jalan utama telah beraspal. Sedangkan untuk masuk kedalam beberapa dusun dapat melewati jalan yang sudah dicor beton.

Desa Serut memiliki 7 dusun yang didalamnya terdapat 7 RW dan 38 RT. Sedangkan untuk jumlah penduduk menurut jenis kelamin yang diupdate pada 2016, terdapat 2.516 penduduk laki laki dan 2.648 penduduk perempuan. Sehingga menurut

\begin{abstract}
Abstrak - Jurnal ini dibuat dengan tujuan untuk memenuhi ketentuan untuk menyelesaikan kegiatan Kuliah Kerja Nyata (KKN) yang ke 79 yang dilaksanakan oleh Universitas Atma Jaya Yogyakarta pada tahun 2021. Lokasi yang dijadikan objek KKN untuk tim penulis adalah desa Serut yang berada di kecamatan Gedangsari, kabupaten Gunungkidul, provinsi Daerah Istimewa Yogyakarta. Tema yang diangkat oleh tim penulis adalah potensi dari desa Serut. Tim penulis mencari data dan informasi mengenai desa Serut melalui internet dengan melakukan analisis melalui website resmi desa Serut dan website lainnya yang berhubungan, dan beberapa jurnal terkait. Tim penulis menemukan potensi yang dimiliki oleh desa Serut adalah potensi untuk desa wisata dan potensi sumber daya alam yaitu penghasil kayu Jati dan kayu Bambu. Program yang tim penulis buat ini diharapkan dapat membantu warga desa Serut untuk dapat mengembangkan lagi potensi yang dimiliki oleh desanya.
\end{abstract}

Kata Kunci - Potensi Desa, Desa Wisata, Potensi Sumber Daya Alam.

update terakhir 2016 terdapat 5.164 penduduk yang mendiami desa Serut.

Desa Serut memiliki beberapa potensi yang dimanfaatkan masyarakat desa untuk menunjang perekonomian mereka. Potensi tersebut berupa potensi alam dan potensi usaha. Potensi alam yang dimiliki desa Serut adalah wisata Gunung Jambu. Gunung Jambu merupakan upaya masyarakat desa untuk memajukan pariwisata dengan memanfaatkan potensi alam yang ada. Gunung Jambu merupakan tempat yang menawarkan keindahan alam dari puncak ketinggian. Selain itu Gunung Jambu juga sering dimanfaatkan untuk wisata yang memacu adrenalin seperti offroad dan motor trail. Di dalam Gunung Jambu juga terdapat situs candi bersejarah yakni Candi Manikmoyo yang sering digunakan untuk ritual dan bertapa.

Potensi usaha yang dimiliki desa Serut adalah potensi bambu dan potensi pohon jati. Tanaman bambu dapat dimanfaatkan menjadi berbagai keperluan seperti furniture, kerajinan, bahan bangunan, konsumsi, dan lainnya. Tanaman bambu merupakan tanaman yang masuk dalam kategori keluarga rumput-rumputan. Di Indonesia terdapat 
60 jenis bambu yang ditemukan di berbagai daerah dataran rendah sampai dataran tinggi dengan ketinggian $300 \mathrm{mdpl}$. Tidak hanya bambu, terdapat pula pohon jati yang dimanfaatkan menjadi bahan baku pembuatan furniture dan bahan bangunan dari rumah tradisional. Jati merupakan tanaman yang mendominasi hutan rakyat di Gunung Kidul. Pada tahun 2007, terdapat $60.000 \mathrm{~m} 3$ kayu jati dari Gunung kidul. Jati yang dihasilkan disalurkan ke daerah industri pengolahan kayu yakni Klaten, Jepara, Pekalongan, dan daerah di Jawa Tengah. Jenis pohon jati yang ditanam masyarakat desa Serut merupakan jenis Jati Unggul Nusantara. Jati Unggul Nusantara merupakan jenis tanaman jati yang memiliki tingkat pertumbuhan cepat dengan bayang yang lurus dan bulat.

\section{METODE PENGABDIAN}

Penelitian ini menggunakan metode penelitian kualitatif deskriptif yang menggunakan analisis secara detail. Penelitian ini dilaksanakan di Desa Serut, Kecamatan Gedangsari, Kabupaten Gunungkidul. Teknik pengumpulan data pada penelitian ini menggunakan metode dokumentasi. Seluruh data dan informasi yang digunakan pada penelitian ini bersumber dari berbagai website resmi yang memuat berbagai data dan informasi mengenai Desa Serut yang berarti penelitian ini memanfaatkan data sekunder sebagai sumber data dan informasi. Data sekunder sendiri merupakan data yang diperoleh atau dikumpulkan oleh orang yang melakukan penelitian dari sumber-sumber yang telah ada[1]. Pengumpulan data dilakukan menggunakan internet dikarenakan mengingat pelaksanaan penelitian pada kali ini terdapat berbagai kendala yang disebabkan oleh pendemi Covid-19 yang sedang dialami Indonesia dan berbagai negara lainnya di seluruh dunia.

Penelitian Mengenai Potensi Desa:

Tentunya setiap daerah memiliki potensi yang berbeda-beda yang dipengaruhi oleh banyak faktor di dalamnya. Maka sangatlah diperlukan suatu cara pengembangan meningkatkan potensi desa yang dimiliki dengan harapan dapat menjadi suatu ciri khas bagi daerah tersebut. Desa Serut memiliki banyak potensi yang dapat lebih dikembangkan seperti potensi dari sektor wisata, dan wirausaha. Namun, kali ini kami ingin memberikan suatu gambaran untuk meningkatkan potensi dari sektor wirausaha dengan mengenalkan kerajinan bambu yang bisa digunakan menjadi kerajinan yang bermanfaat.

Setelah proses pengumpulan data, maka untuk proses analisisnya penelitian ini menggunakan metode analisis deskriptif. Menurut Sugiyono (2014:21) metode analisis deskriptif adalah statistic yang digunakan untuk menganalisis data dengan cara mendeskripsikan atau menggambarkan data yang telah terkumpul sebagaimana adanya tanpa bermaksud membuat kesimpulan yang berlaku untuk umum atau generalisasi[2].

\section{HASIL DAN PEMBAHASAN}

A. Pengolahan bambu menjadi bahan anyaman

Ide pengembangan usaha yang diusulkan oleh kelompok adalah ide kewirausahaan dengan memanfaatkan pengolahan tanaman bambu yang ada di Desa Serut menjadi beberapa produk kerajinan. Populasi dari tanaman bambu kurang dimanfaatkan secara maksimal oleh masyarakat sekitar. Tanaman bambu hanya dipakai sebagai keperluan pribadi saja dan tidak ada tujuan ke pemasaran. Adapun beberapa hasil yang dimanfaatkan oleh masyarakat tersebut seperti bahan baku pembuatan kandang ternak, pembuatan tampah, dan dijual kepada pihak ketiga yang membutuhkan.

Sebelum dibuat menjadi beberapa kerajinan, terdapat beberapa tahapan yang harus dilakukan untuk mengolah bambu menjadi bahan baku yang siap digunakan sebagai bahan pembuatan kerajinan, antara lain : pemilihan bambu, pemotongan, pembersihan, pengeringan, pewarnaan, pengawetan, dan proses penganyaman. Jenis bambu yang digunakan sebenarnya dapat bermacam-macam, akan tetapi jenis yang tersedia di daerah Gunungkidul terkhusus Desa Serut ini adalah jenis bambu Jawa (bambu apus). Setelah didapatkan bambu dengan kualitas yang baik langkah selanjutnya yakni proses pemotongan bambu yang dapat memanfaatkan alat potong tradisional seperti parang ataupun alat potong menggunakan mesin serkel untuk mendapat hasil yang rapi. Langkah selanjutnya yakni pembersihan, pembersihan dilakukan dengan menggunakan alat boding proses pembersihan ini bertujuan untuk memperoleh hasil yang rapi dan menghilangkan serabut-serabut bekas sisa dari pemotongan. Setelah dilakukan pembersihan selanjutnya bambu tersebut dikeringkan dibawah sinar matahari secara langsung untuk menghilangkan kadar air yang masih terkandung dalam bambu tersebut. Proses pengeringan memakan waktu 1-3 hari tergantung dari cuaca. Setelah melalui proses pengeringan, selanjutnya masuk ke dalam tahap pewarnaan. Proses pewarnaan dilakukan dengan merebus bahan ke dalam larutan yang telah dicampur pewarna sintetis wenter. Dalam proses pewarnaan, perbandingan air dengan pewarna disesuaikan dengan kebutuhan yang diinginkan. Bahan tersebut dimasukkan ke dalam campuran yang mendidih 
kemudian dibiarkan direbus selama 15 menit dan terus diaduk-aduk. Setelah proses perebusan, bahan tersebut diangkat dan diangin-anginkan selama 12 jam agar warna dapat melekat dengan sempurna pada bahan. Selanjutnya adalah proses pengawetan bahan, pengrajin dapat menggunakan hidrogen peroksida (H2O2) dengan cara mencampurkan $\mathrm{H} 2 \mathrm{O} 2$ dengan air bersih kemudian diaduk rata dan memasukkan bahan ke dalam campuran tersebut dan merendamnya selama 24 jam. Setelah itu diangkat dan dibersihkan lalu dikeringkan dengan menjemurnya. tujuan dari pengawetan ini adalah agar bahan tidak mudah rusak oleh jamur dan rayap.

\section{B. Ide pembuatan kerajinan}

Pembuatan kerajinan muncul karena keinginan untuk memaksimalkan pemanfaatan bambu sehingga dapat menambah nilai jual di pasaran. Karena produksi sebelumnya menghasilkan produk setengah jadi, maka dalam pembuatan kerajinan ini tujuannya adalah memanfaatkan produk setengah jadi tersebut menjadi produk jadi untuk dijual ke pasaran.

\section{Pembuatan wadah rokok}

Dalam pembuatan wadah rokok, ada beberapa tahapan yang harus dilakukan untuk mengolah bambu anyaman menjadi sebuah produk kerajinan, berikut adalah prosesnya :

a. Tahap pertama adalah penyiapan bahan baku berupa hasil anyaman dari bambu apus yang sudah diraut dan melalui seluruh proses pewarnaan dan pengawetan.

b. Tahap kedua adalah pembuatan pola atau desain pada anyaman bambu menggunakan pensil dan penggaris. Setelah pola berhasil dibuat, selanjutnya pemberian garis luar untuk keperluan pemotongan menggunakan spidol. Anyaman bambu tersebut dipotong menurut pola desain yang telah dibuat menggunakan alat potong berupa gunting.

c. Tahap ketiga adalah mulai membuat tangkai untuk wadah rokok dengan cara meraut tangkai menggunakan pisau raut kemudian diberi lapisan lem dan bensin agar tidak mudah dimakan oleh rayap.

d. Tahap keempat yakni pembuatan lapisan tepi pada wadah rokok dengan anyaman dan dibantu dengan pisau raut hingga berbentuk menyerupai persegi.

e. Tahap kelima adalah pembuatan kerangka wadah rokok dengan cara menempelkan hasil pemotongan tangkai yang sudah berbentuk persegi dengan cara dipaku pada bagian ujung-ujungnya untuk memperkuat rekatannya.

f. Setelah direkatkan dengan menggunakan paku, rangka tersebut kemudian di lem dengan lem yang dicampur bensin untuk merekatkan sisi-sisi yang masih belum menempel.

g. Setelah pengeleman hasil anyaman bambu lalu ditempelkan pada kerangka yang berbentuk persegi dan merekatkannya menggunakan lem, lalu biarkan mongering.

h. Setelah mengering dan produk sudah jadi, produk dibersihkan serat yang masih menempel pada sisi-sisinya menggunakan api kecil dengan cara menempelkan wadah rokok ke api kecil lalu membersihkannya menggunakan kuas.

i. Setelah wadah rokok dibersihkan, langkah selanjutnya adalah perendaman menggunakan larutan $\mathrm{H} 2 \mathrm{O} 2$ yang dicampur dengan air selama semalaman, yang berguna untuk memutihkan/mencerahkan warna dari produk sehingga menarik ketika dilihat dan bertujuan sebagai pengawetan agar tidak terkena serangan rayap.

j. Setelah dikeringkan dari proses pemutihan, selanjutnya adalah pemberian impra dengan cara melumaskan larutan impra menggunakan kuas ke seluruh bagian wadah rokok. Impra adalah cairan yang biasa digunakan dalam finishing produk kayu yang bertujuan untuk mengkilapkan dari suatu produk agar terlihat menarik.

\section{Pembuatan tudung lampu}

Cahaya merupakan suatu unsur penting dalam suatu ruangan. Sumber cahaya bisa didapatkan secara alami maupun buatan. Sumber cahaya alami didapatkan dari sinar matahari yang masuk melalui sela-sela ruangan maupun jendela. Sedangkan sumber cahaya buatan bisa didapatkan dari lampu yang dialiri oleh listrik. Untuk menambah unsur estetika ruangan, seringkali lampu dihiasi dengan tudung lampu agar terlihat lebih menarik dan mempercantik ruangan. Salah satu bahan yang dapat dimanfaatkan sebagai objek pembuatan tudung lampu adalah bambu, karena tanaman ini mudah ditemukan dan memiliki harga yang terjangkau serta memiliki daya tahan yang relatif lama apabila diberikan perlakuan. Berikut adalah tahap-tahap pembuatan tudung lampu berbahan bambu.

a. Tahap pertama adalah pemilihan bambu, bambu yang dipilih adalah bambu yang berusia tidak terlalu tua dan sudah 
dibiarkan selama 5-6 hari agar benar-benar kering

b. Memotong bambu menjadi berukuran 11,5 meter sesuai kebutuhan

c. Menghaluskan permukaan bambu hingga halus menggunakan amplas

d. Melakukan pelapisan permukaan bambu menggunakan cat sehingga tampilannya lebih indah dan tahan terhadap serangan rayap

e. Menentukan ruas yang akan dijadikan dudukan lampu hias kemudian memotongnya menggunakan gergaji, selanjutnya melubangi ujung lain untuk dijadikan keluarnya cahaya lampu

f. Menghaluskan ujung yang telah digergaji menggunakan amplas

g. Melubangi bagian tengah bambu untuk jalur penyambungan kabel

h. Membuat dudukan dari semen agar lampu hias dapat berdiri secara tegak dengan tinggi dudukan $8 \mathrm{~cm}$.

i. Untuk membuat tampilan lampu menjadi lebih menarik, diberikan ukiran dan pahatan pada badan tudung lampu.

j. Selanjutnya masukkan bohlam lampu ke dalam tudung bambu dan menyambungkan semua komponen kabel.

\section{Strategi Pemasaran Produk}

Setelah produk kerajinan selesai dibuat, langkah selanjutnya adalah memasarkan produk untuk dijual ke masyarakat. Pemasaran dilakukan dengan langkah awal yaitu promosi. Promosi dilakukan secara langsung maupun tidak langsung.

\section{a. Promosi langsung}

Promosi langsung dilakukan dengan cara menawarkan produk kepada konsumen secara langsung tanpa melalui perantaraan apapun. Promosi secara langsung dapat dilakukan dengan beberapa cara yakni dari pintu ke pintu, bazar atau pameran, dan word of mouth. Promosi pintu ke pintu dilakukan dengan cara interaksi antara individu yang saling bertatap muka yang bertujuan menimbulkan transaksi. Tujuan promosi melalui bazar adalah agar menarik minat konsumen terhadap barang yang diproduksi karena di dalam bazar memiliki kemungkinan yang lebih besar untuk mendapatkan konsumen. Selain itu di dalam pameran juga akan mudah ditemui konsumen terhadap produk kerajinan, karena mayoritas dari konsumen akan mencari produk perabotan kerajinan dalam pameran. Strategi word of mouth dilakukan melalui pembicaraan dari mulut ke mulut dengan cara menceritakan keunggulan serta kelebihan dari produk yang dimiliki ke masyarakat.

\section{b. Promosi tidak langsung}

Promosi secara tidak langsung adalah promosi dengan memanfaatkan berbagai media seperti media cetak, media sosial, radio. Promosi yang dilakukan melalui media sosial dinilai akan lebih efektif karena modal yang dikeluarkan untuk biaya promosi sangat terjangkau dan dapat menjangkau masyarakat lebih luas. Karena di era digitalisasi seperti sekarang mayoritas penduduk di Indonesia memiliki akun media sosial mereka masing-masing.

\section{KESIMPULAN}

Memandang desa sebagai basis potensial kegiatan ekonomi haruslah menjadi paradigma baru dalam program pembangunan ekonomi Indonesia secara keseluruhan. Perubahan kondisi internal dan eksternal yang terjadi menuntut kebijakan yang tepat dan matang dari para pembuat kebijakan dalam upaya pengembangan potensi wilayah pedesaan. Sudah saatnya menjadikan desa sebagai pusat-pusat pembangunan dan menjadikan daerah ini sebagai motor utama penggerak roda perekonomian. Dalam hal ini desa serut dapat melakukannya melalui sektor pariwisata dengan pengembangan desa sebagai desa wisata dan sektor industri sebagai penghasil kayu jati dan kayu bambu.

Kedua sektor tersebut dapat menjadi pilihan model modernisasi desa serut, dimana modernisasi ini haruslah dapat meningkatkan kesempatan kerja dan pendapatan wilayah setempat, untuk itu perancangan perencanaan pembangunan desa wisata dan industri kayu bambu dan jati perlu disesuaikan dengan karakteristik wilayah dan ketersediaan teknologi tepat guna. Sehingga alokasi sumber daya dan dana yang terbatas, dapat menghasilkan output yang optimal, yang pada akhirnya wajib berdampak positif terhadap kesejahteraan masyarakat. Agar model pembangunan pedesaan yang berkelanjutan dapat terwujud diperlukan pedoman pengelolaan sumber daya melalui pemahaman wawasan pariwisata dan industri secara bijak, yaitu pemanfaatan aset-aset untuk kegiatan ekonomi tanpa mengesampingkan aspek-aspek pelestarian lingkungan.

\section{SARAN}

Dari kesimpulan yang kami simpulkan diatas, maka kami bisa mengusulkan beberapa saran yang bisa menjadi acuan dalam penerapan konsep dan strategi pengembangan yang akan diterapkan 
dalam perencanaan di Desa Serut pada masa yang akan datang antara lain :

1. Membuat pemasaran dan promosi wisata dan hasil olahan dari desa serut yang sesuai dengan masa kini, bisa menggunakan sosial media instagram, facebook, twitter, ataupun hingga membuat website khusus untuk desa wisata serut.

2. Mengelola sarana dan prasarana yang ada di tiap tempat wisata dengan baik, bisa dimulai dari akses jalan menuju tempat wisata, sarana kebersihan seperti kamar mandi di tempat wisata, hingga kebersihan dan keasrian dari masing-masing tempat wisata

3. Memberikan penyuluhan dan pelatihan kepada masyarakat mengenai pengolahan kayu jati dan bambu hingga dapat menghasilkan luaran yang bisa diperjual belikan dalam bentuk mentah maupun bentuk jadi seperti kerajinan tangan.

\section{DAFTAR PUSTAKA}

[1]A. Khozin, "Persepsi Pemustaka Tentang Kinerja Pustakawan Pada Layanan Sirkulasi Di Perpustakaan Daerah Kabupaten Sragen," Menejemen, pp. 30-39, 2013, [Online]. Available: http://eprints.undip.ac.id/40779/3/BAB III.pdf.

[2]K. Adam and D. Steffi, "Metopen," 12, p. 12, 2015 .

[3]S. Asti Mulasari, M. Waldami Dwi Wibowo, A. Irjayanti, and E. Nurmalasari, "Peningkatan Sumberdaya Manusia Melalui Gedangsari Festival," BERDIKARI J. Inov. dan Penerapan Ipteks, vol. 7, no. 1, pp. 90-97, 2019, doi: 10.18196/bdr.7160.

[4]D. Andriani, "Seminar hasil penelitian," pp. 113, 2007.

[5] G. W. Setiawan, S. D. Susanto, M. E. Rachmadi, B. M. Enda, and F. T. Adevita, "Edukasi pengolahan dan pemasaran sebagai bentuk pemanfaatan tanaman bambu di desa Melikan," vol. 1, no. 1, pp. 53-58, 2021.

[6] D. P. M. dan P. Terpadu, "Deskripsi Wilayah Kabupaten Gunungkidul," Profil Investasi Kabupaten Gunungkidul, vol. 53, no. 9, pp. 16891699, 2016, [Online]. Available: https://dpmpt.gunungkidulkab.go.id/upload/gallery/ 6db270732e28968cac4520db34a9f4f2_buku profil inves 2016.pdf

[7] R.- Hidayat, “Sejuta Bambu Untuk Indonesiaku' Socio-Ecopreuneur Untuk Mensejahterakan Pengrajin Bambu Di Desa Hargomulyo, Gedangsari, Gunung Kidul, Yogyakarta Dalam Momentum Masyarakat Ekonomi Asean( Mea)," J. Pengabdi. Barelang, vol. 1, no. 01, p. 16, 2019, doi: 10.33884/jpb.v1i01.959.

[8] Tim Kerja Kementerian Dalam Negeri, "Pedoman Umum Menghadapi Pandemi Covid-19 Bagi Pemerintah Daerah: Pencegahan, Pengendalian, Diagnosis dan Manajemen," J. Chem. Inf. Model., vol. 53, no. 9, pp. 1689-1699, 2013, doi: 10.1017/CBO9781107415324.004.

[9] "STUDI MUTU KAYU JATI DI HUTAN RAKYAT GUNUNGKIDUL I. PENGUKURAN LAJU PERTUMBUHAN SRI NUGROHO MARSOEM Bagian Teknologi Hasil Hutan, Fakultas Kehutanan, Universitas Gadjah Mada, Yogyakarta," pp. 108-122.

[10] A. S. Widiastuti et al., "Potensi Masyarakat Desa Serut melalui Peremajaan Pariwisata Gunung Jambu," vol. 1, pp. 515-516, 2019.

[11] M. Dzakiyah, U. Latifatuzzahro, E. Ritonga, and ..., "Pendampingan Kelompok Sadar Wisata dan Strategi Pengembangan Objek Wisata Gunung Jambu Gunungkidul, DIY," Pros. Konf. ..., vol. 1, pp. 327-332, 2019, [Online]. Available: http://sunankalijaga.org/prosiding/index.php/abdim as/article/download/250/227.

[12] M. Dzakiyah, U. Latifatuzzahro, E. Ritonga, and ..., "Pendampingan Kelompok Sadar Wisata dan Strategi Pengembangan Objek Wisata Gunung Jambu Gunungkidul, DIY," Pros. Konf. ..., vol. 1, pp. 327-332, 2019, [Online]. Available: http://sunankalijaga.org/prosiding/index.php/abdim as/article/download/250/227.

[13]K. AYU HARI MURTI, "Kerajinan Anyam Bambu Di Sanggar Hamid Jaya Desa Gintangan Kecamatan Rogojampi Kabupaten Banyuwangi," J. Seni Rupa, vol. 6, no. 01, pp. 634-644, 2018. 


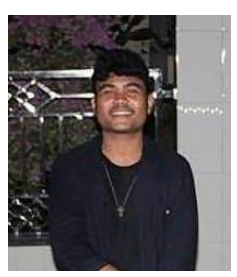

Hernandi Aditya Prong, Prodi Ilmu Hukum, Fakultas Hukum,Universitas Atma Jaya Yogyakarta.

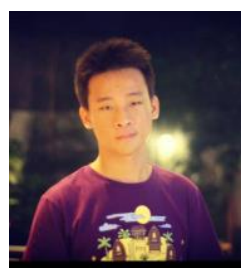

Hendrianto, Prodi Informatika, Fakultas Teknologi Industri, Universitas Atma Jaya Yogyakarta.

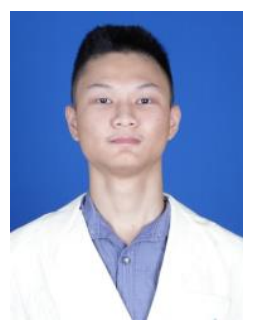

Hizkia Pilar Tiarso, Prodi Informatika, Fakultas Teknologi Industri, Universitas Atma Jaya Yogyakarta.

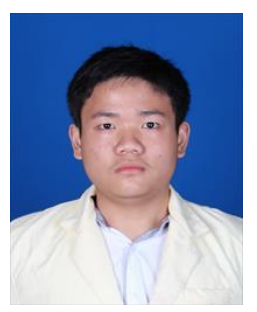

Hans Audianto Kurniawan, Prodi Sistem Informasi, Fakultas Teknologi Industri, Universitas Atma Jaya Yogyakarta.

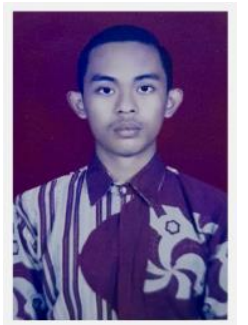

Satrio Adi Pamungkas, Prodi Sosiologi, Fakultas Ilmu Sosial dan Politik,Universitas Atma Jaya Yogyakarta.

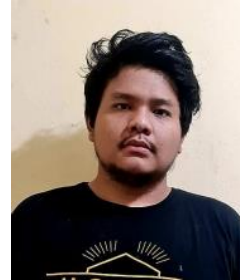

Agam Nicholas Prodi Teknik Sipil, Fakultas Teknik ,Universitas Atma Jaya Yogyakarta.

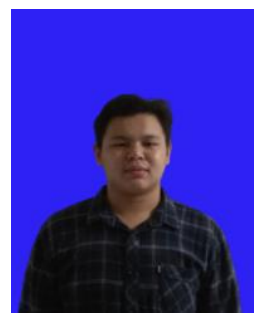

Febryanto Pratama Prodi Teknik Sipil, FAKULTAS TEKNIK,Universitas Atma Jaya Yogyakarta.

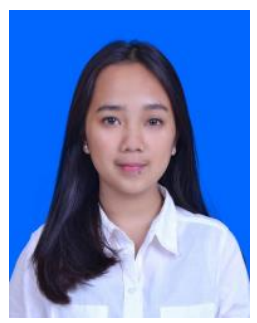

Laksmay Alshika Purmitasari, Departemen Ilmu Komunikasi, Fakultas Ilmu Sosial dan Politik, Universitas Atma Jaya Yogyakarta.

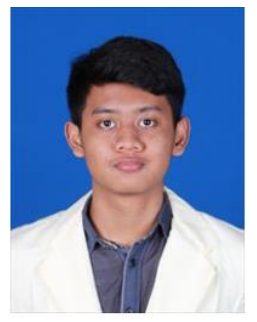

Wemar Adhie Lovely, Prodi Teknik Industri, Fakultas Teknologi Industri, Universitas Atma Jaya Yogyakarta

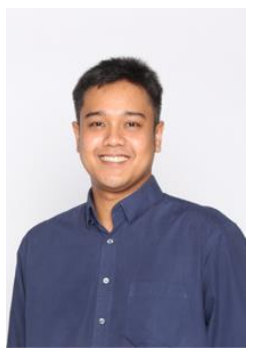

Meganusa

Ludvianto, Departemen Ilmu Komunikasi, Fakultas Ilmu Sosial dan Ilmu Politik, Universitas Atma Jaya Yogyakarta 